\title{
Development of Tolerance to Morphine Antinociception in Mice Treated with Nociceptive Stimulants
}

\author{
A.F.M. Mohibur Rahman, Masakatsu Takahashi and Hiroshi Kaneto \\ Department of Pharmacology, Faculty of Pharmaceutical Sciences, Nagasaki University, 1-14, Bunkyo-machi, Nagasaki 852, Japan
}

Received March 15, $1993 \quad$ Accepted June 8, 1993

\begin{abstract}
We have examined whether or not the presence of pain can block the development of tolerance to morphine antinociception in mice. A single injection of formalin or Freund complete adjuvant into the dorsal part of one side of the hind paw resulted in a significant swelling of the treated paw which lasted more than 5 days. In formalin-treated animals that received the initial morphine $2 \mathrm{hr}$ after the stimulant, the development of tolerance to morphine was delayed without affecting morphine antinociception when the effect was measured daily by the tail-pinch (TP) method but not by the tail-flick (TF) method. However, the stimulant suppressed tolerance development even in the TF method unless the daily measurement was undertaken. When morphine injection was started from 5 days after the formalin injection, tolerance developed in a pattern similar to that in the control animals. On the other hand, treatment with Freund adjuvant did not affect the development of tolerance measured by both the TP and TF methods, with or without daily measurement of antinociception. When acetic acid was used as a stimulant, daily morphine was administered before or after the acetic acid injection, in the presence or absence of pain, tolerance developed to the same extent as in the control group, regardless of the time of morphine injection. Thus, our results suggest that the development of tolerance to narcotics may be modified by various factors, such as the type and intensity of nociception; and they also suggest that different results may be produced depending on the test method.
\end{abstract}

Keywords: Antinociceptive tolerance, Morphine, Nociceptive stimulant, Chronic pain

It has been reported that tolerance does not develop to narcotic analgesics when nociceptive stimuli are applied concomitantly (1), and similar suppression of the development of tolerance to morphine or bezitramide has been demonstrated in arthritic rats $(2,3)$. In contrast, Kayser and Guilbaud (4) and Kayser et al. (5) have observed the development of complete tolerance to morphine in arthritic animals. Clinically, it is reported that patients with chronic pain, such as chronic abdominal or back pain (6) and various types of other chronic pain including cancer pain (7), were able to receive long term treatment with opiates without the development of analgesic tolerance $(6,7)$. Thus, whether chronic pain or sufficient nociceptive stimuli or a pathological state can prevent the development of tolerance to narcotics is still a subject of controversy.

Difficulties encountered in the preparation of chronic pain models may be one of the most important factors responsible for producing the discrepancies in animal experiments. Thus in the present study, using 3 different nociceptive stimulants, formalin, Freund adjuvant and acetic acid, and 3 different methods, tail-pinch (TP), tailflick (TF) and acetic acid writhing, for evaluating the antinociceptive effect, whether and what type of nociception can block the development of tolerance to morphine antinociception were investigated in mice.

\section{MATERIALS AND METHODS}

\section{Animals}

Conventional male albino mice of the ddY strain, weighing 20 to $25 \mathrm{~g}$, were used throughout the experiments. Animals were housed in a temperature controlled room, at $22 \pm 1{ }^{\circ} \mathrm{C}$, and maintained on a 12-hr light/dark cycle, and were supplied laboratory diet and tap water ad libitum.

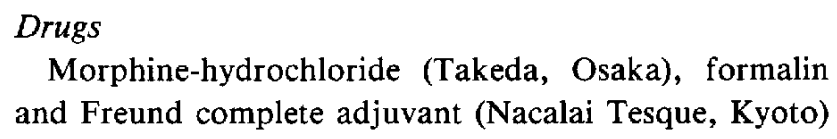

Morphine-hydrochloride (Takeda, Osaka), formalin and Freund complete adjuvant (Nacalai Tesque, Kyoto) 
and acetic acid (Katayama, Osaka) were used.

\section{Induction of inflammation}

Twenty microliters of 1.0 or $2.0 \%$ formalin or 10 or 20 $\mu l$ of Freund complete adjuvant was injected into the dorsal part of one side of the hind paw. The control group was treated with saline instead of stimulants. After a single injection of formalin or adjuvant, the thickness of the treated paw was measured daily for 5 days with slide callipers and compared with that of the control group on the respective day.

\section{Evaluation of antinociceptive effect}

The antinociceptive effect was measured by the tailpinch (TP) method using forceps or the tail-flick (TF) method using a tail-flick analgesia meter (MK-330; Muromachi, Tokyo). The intensity of the pressure and the radiant heat was set to provide a predrug latency time of $0.7-1.3 \mathrm{sec}$ (a cutoff time of $6 \mathrm{sec}$ ) and $2-4 \mathrm{sec}$ (a cutoff of $10 \mathrm{sec}$ ), respectively, in the TP and TF test. Measurements were made every $15 \mathrm{~min}$ after the administration of morphine for a period of $90 \mathrm{~min}$, and the effect was expressed as the area under the time-response curve (AUC), by plotting the increase in response time (sec) on the ordinate and the time interval (min) on the abscissa. In the acetic acid writhing test, after i.p. injection of $0.6 \%$ acetic acid, the number of writhes elicited during a 5 -min period were counted 5 times alternatively at intervals of $5 \mathrm{~min}$ for $45 \mathrm{~min}$ and expressed as the sum of the writhes.

\section{Assessment of tolerance}

In the TP and TF tests, the AUC of $10 \mathrm{mg} / \mathrm{kg}$ of morphine, s.c. was measured daily or on the 6th day; and a significant decrease of AUC, compared with that of the 1st day, indicated the development of tolerance. Administration of morphine was started from $2 \mathrm{hr}$ after the formalin injection or the adjuvant treatment. In the acetic acid $(\mathrm{AcOH})$ writhing test, mice were treated once or twice daily with $0.6 \% \mathrm{AcOH}$ alone, $\mathrm{AcOH}$ at $15 \mathrm{~min}$ before morphine or $\mathrm{AcOH}$ at $15 \mathrm{~min}$ after morphine for 5 days; the test dose of morphine, $1 \mathrm{mg} / \mathrm{kg}$, s.c., was given $10 \mathrm{~min}$ before the $\mathrm{AcOH}$ injection, and the number of writhes induced by $\mathrm{AcOH}$ was counted in alternate 5-min periods for $45 \mathrm{~min}$ on the 6 th day.

\section{Statistical analyses}

Results were expressed as the mean \pm S.E. Following analysis of variance for repeated measures of the overall data to assess statistical significance, differences between the individual mean values in different groups were analyzed by Dunnett's test.

\section{RESULTS}

\section{Paw swelling}

One hour after a single injection of formalin and adjuvant, a significant swelling was produced in the treated paw. The effect was dose-dependent and lasted for more than 5 days (Fig. 1). These groups of mice did not receive morphine treatment and were subjected to the measurement of swelling and observation of pathological changes.

\section{Development of tolerance}

In formalin-treated mice: Daily injection of morphine at the dose of $10 \mathrm{mg} / \mathrm{kg}$ resulted in the development of tolerance in the control animals regardless of the test methods. In the animals treated with formalin, however, the development of tolerance was significantly delayed compared with that of the control group when the antinociceptive effect was measured by the TP method, as substantiated by the sustained intensity and duration of the antinociceptive effect on the 5th day, which was comparable to that on the 1st day. In contrast, formalin treatment did not affect the development of tolerance when the test was performed by the TF method (Fig. 2). As seen in the data of the 1st day, the stimulants did not affect the antinociceptive effect of morphine.

Meanwhile, even when the antinociceptive effect was measured only on the final day, mice treated with morphine alone for 5 days developed tolerance to the effect in both methods; however, the development of tolerance
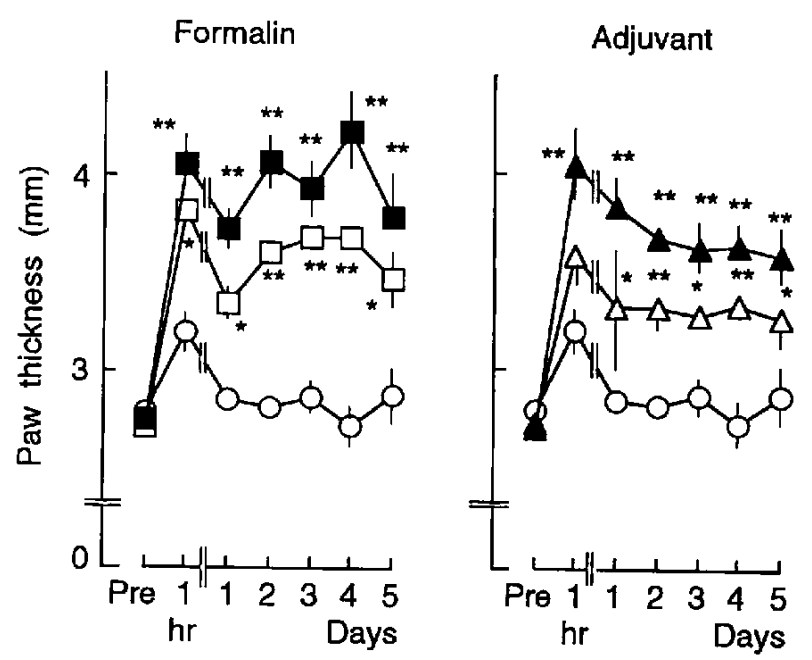

Fig. 1. Induction and duration of inflammation after a single injection of formalin or Freund adjuvant. Twenty microliters of $1.0(\square)$ or $2.0(\square) \%$ formalin (left) or $10(\triangle)$ or $20(\Delta) \mu l$ of Freund adjuvant (right) was injected into the dorsal part of the hind paw. Each point indicates the mean \pm S.E. $(n=6)$. Significantly different from the saline-treated control group $(\bigcirc),{ }^{*} \mathrm{P}<0.05,{ }^{* *} \mathrm{P}<0.01$. 

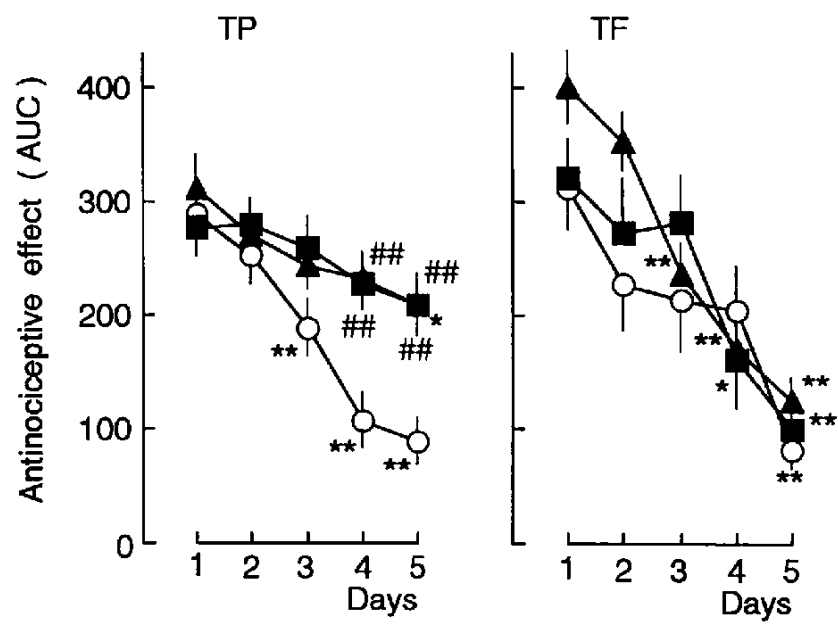

Fig. 2. Development of tolerance to morphine antinociception in the formalin-treated mice. Two hours after the injection of $2.0(\mathbb{a})$ and $5.0(\mathbf{\Lambda}) \%$ formalin, morphine at $10 \mathrm{mg} / \mathrm{kg}$, s.c. was administered daily; and subsequently, the antinociceptive effect was measured by the tail-pinch (TP) or tail-flick (TF) methods for 5 successive days. The control group $($ ) was treated with saline instead of formalin. Each point indicates the mean \pm S.E. $(n=10-20)$. Significantly different from the corresponding value on the 1st day, ${ }^{*} \mathrm{P}<0.05,{ }^{* *} \mathrm{P}<0.01$. Significantly different from the effect in the control group on the respective days, ${ }^{\# \prime} \mathrm{P}<0.01$.
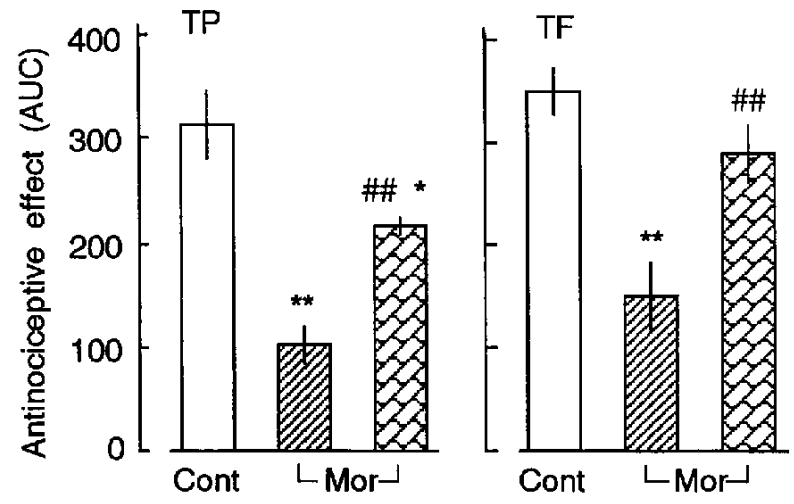

Fig. 3. Development of tolerance to morphine in the formalin treated mice omitting the daily test for antinociception. Two hours after the injection of $2.0 \%$ formalin, morphine at $10 \mathrm{mg} / \mathrm{kg}$, s.c. was administered daily for 6 days; and after the final injection of morphine, the antinociceptive effect was measured once by the tailpinch (TP, left panel) or tail-flick (TF, right panel) methods. Morphine group treated with saline instead of formalin (Mor, with formalin (Mor, $\square Z$ ). The control group (Cont, $\square$ ) received a single morphine dose of $10 \mathrm{mg} / \mathrm{kg}$, s.c. on the test day. Each column indicates the mean \pm S.E. $(n=10-20)$. Significantly different from the control group, ${ }^{*} \mathrm{P}<0.05,{ }^{* *} \mathrm{P}<0.01$. Significantly different from the morphine group treated with saline, ${ }^{A *} \mathrm{P}<0.01$.

was delayed and suppressed, respectively, in the formalin treated mice in the TP and TF methods (Fig. 3).

When morphine injection was started from 5 days after



Fig. 4. Development of tolerance to morphine antinociception in mice started from the 5 th day of formalin treatment. Five days after the injection of $2.0(\square) \%$ formalin, morphine at $10 \mathrm{mg} / \mathrm{kg}$, s.c. was administered daily; and subsequently, the antinociceptive effect was measured by the tail-pinch (TP) method for 5 successive days. The control group $(O)$ was treated with saline instead of formalin. Each point indicates the mean \pm S.E. $(n=10-20)$. Significantly different from the corresponding value on the 1 st day, ${ }^{* *} \mathrm{P}<0.01$.

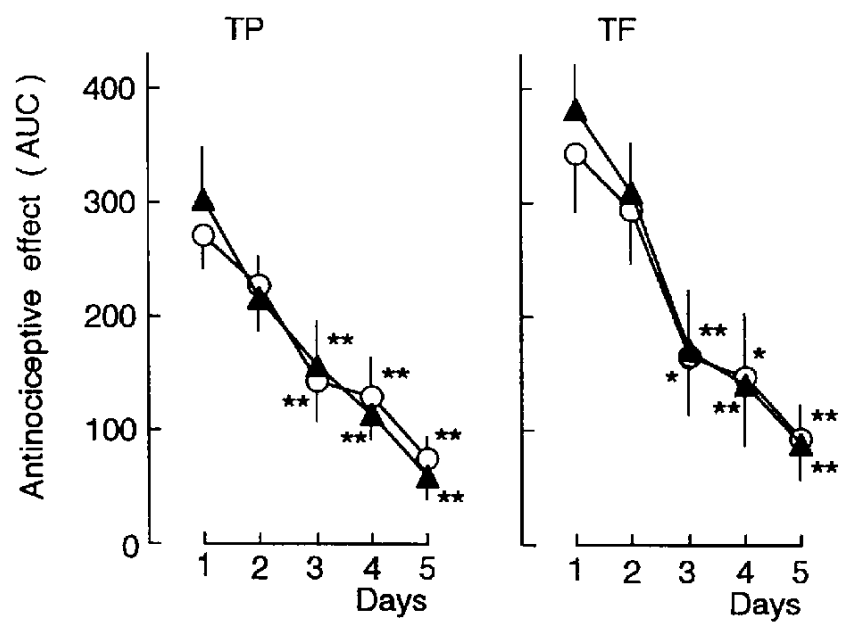

Fig. 5. Development of tolerance to morphine antinociception in the Freund adjuvant-treated mice. Two hours after the injection of $20 \mu \mathrm{l}$ of Freund adjuvant $(\boldsymbol{A})$, morphine at $10 \mathrm{mg} / \mathrm{kg}$, s.c. was administered daily for 5 days. The control group (O) was treated with saline. The antinociceptive effect was measured by the tail-pinch (TP) and tail-flick (TF) methods. Each point indicates the mean \pm S.E. $(n=8)$. Significantly different from the corresponding value on the 1 st day, ${ }^{*} \mathrm{P}<0.05,{ }^{* *} \mathrm{P}<0.01$.

the formalin injection, tolerance developed in a pattern similar to that in the control animals in the TP method (Fig. 4).

In adjuvant treated mice: Neither the antinociceptive effect of morphine nor the development of tolerance to the effect was affected in the animals treated with Freund 


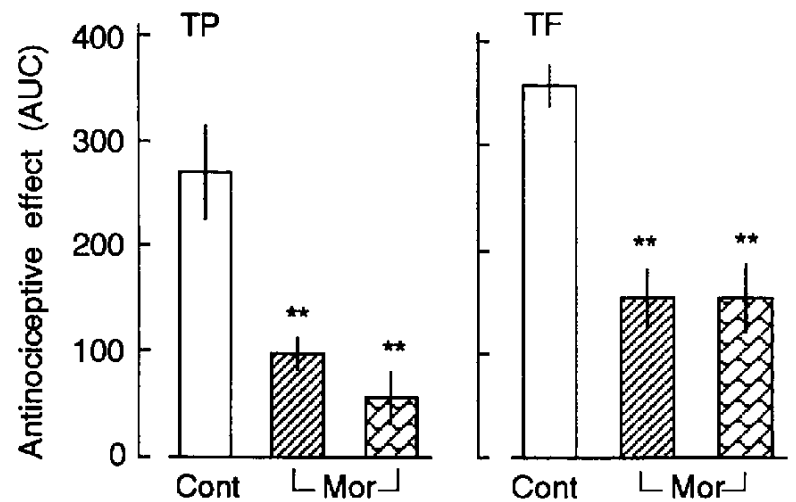

Fig. 6. Development of tolerance to morphine in the Freund adjuvant treated mice omitting the daily test for antinociception. Two hours after the injection of $20 \mu l$ of Freund adjuvant, morphine at $10 \mathrm{mg} / \mathrm{kg}$, s.c. was administered daily for 6 days; and after the final injection of morphine, the antinociceptive effect was measured once by the tail-pinch (TP, left panel) or tail-flick (TF, right panel) methods. Morphine group treated with saline instead of Freund adjuvant (Mor, group (Cont, $\square$ ) received a single morphine dose of $10 \mathrm{mg} / \mathrm{kg}$, s.c. on the test day. Each column indicates the mean \pm S.E. $(\mathrm{n}=10-20)$. Significantly different from the control group, ${ }^{* *} \mathrm{P}<$ 0.01 .

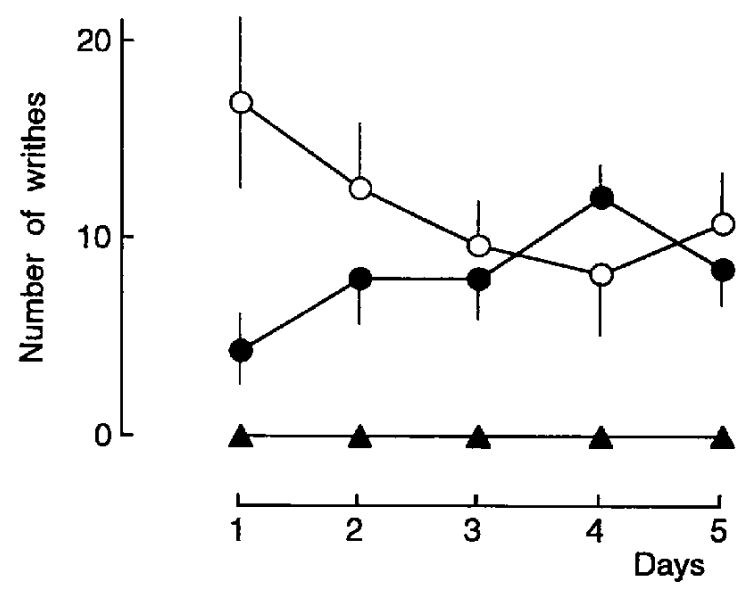

Fig. 7. Daily changes in the number of writhes induced by acetic acid with or without co-administration of morphine. Three groups of mice were treated once daily with 1) $\mathrm{AcOH}(\bigcirc), 2) \mathrm{AcOH}$ at 15 min before morphine (O) or 3) AcOH at 15 min after morphine (A). $\mathrm{AcOH}, 0.6 \%, 10 \mathrm{ml} / \mathrm{kg}$, i.p.; Morphine, $10 \mathrm{mg} / \mathrm{kg}$, s.c. Each point indicates the mean \pm S.E. $(n=7)$.

adjuvant in both TP and TF tests (Fig. 5). Likewise, no substantial differences between the stimulant-treated and untreated groups in the degree of morphine tolerance development were shown when the measurement of antinociception was performed only on the final day (Fig. 6).

In acetic acid treated mice: As a preliminary experiment, daily changes in the number of writhes were count-

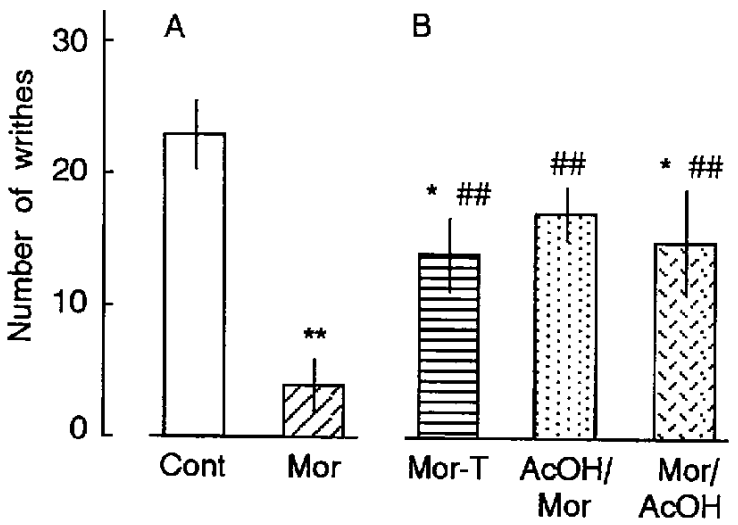

Fig. 8. Development of tolerance to morphine antinociception in the acetic acid-treated mice. (A) Mice were treated twice daily with saline for 5 days. On the 6th day, saline (Cont, $\square$ ) or the test dose of morphine, $1 \mathrm{mg} / \mathrm{kg}$, s.c. (Mor, $叉$ ), was given $10 \mathrm{~min}$ before $\mathrm{AcOH}$ injection; and the number of writhes induced by $\mathrm{AcOH}$ was counted as indicated in the text. (B) Mice received morphine, 10 $\mathrm{mg} / \mathrm{kg}$, s.c., alone (Mor- $\mathrm{T}$, (AcOH/Mor, $\because \because 9$ ); or $\mathrm{AcOH}$ at $15 \mathrm{~min}$ after morphine (Mor/AcOH,, 3$)$, twice daily for 5 days. On the 6 th day, the test dose of morphine, $1 \mathrm{mg} / \mathrm{kg}$, s.c., was given to these groups, and the number of writhes by $\mathrm{AcOH}$ was counted. Each column indicates the mean \pm S.E. $(n=8)$. Significantly different from the salinetreated control group, ${ }^{*} \mathrm{P}<0.05,{ }^{* *} \mathrm{P}<0.01$. Significantly different from the morphine-tolerant group, ${ }^{* *} \mathrm{P}<0.01$.

ed in the groups treated with acetic acid and/or morphine for 5 days. The number of writhes induced by acetic acid tended to decrease day by day, but the changes were statistically insignificant during 5 successive days. When morphine at the dose of $10 \mathrm{mg} / \mathrm{kg}$, s.c. was administered at $15 \mathrm{~min}$ prior to the injection of acetic acid, the induction of writhes was completely suppressed, while in the group treated with morphine at $15 \mathrm{~min}$ after acetic acid, the number of writhes tended to increase slightly, but not significantly (Fig. 7).

In the test on the 6 th day, $1.0 \mathrm{mg} / \mathrm{kg}$ of morphine produced a significant antinociceptive effect, a reduction in the number of writhes in the saline-treated control animals. On the other hand, the same dose of morphine was less effective in the group treated with $10 \mathrm{mg} / \mathrm{kg}$ morphine for 5 days, suggesting the development of tolerance. In the groups treated with acetic acid plus morphine, regardless of the time of morphine injection, the effect of the test dose of morphine was nearly equivalent with that in the group treated with morphine alone for 5 days, indicating the development of the same degree of tolerance (Fig. 8). Five daily injections of acetic acid did not have any substantial influence on the antinociceptive effect of morphine (data not shown). 


\section{DISCUSSION}

In experimental pain model animals, whether tolerance develops to narcotics is still controversial (2-4). A main reason for the discrepancies in the data from animal experiments is due to the difficulties in producing suitable chronic pain status. Arthritis in rats induced by the injection of adjuvant is one of the widely used models of experimental chronic pain $(5,8)$. However, it is open to question whether the arthritic pain may or may not resemble human chronic pain. In the present study, we have employed 3 different nociceptive stimulants, formalin, Freund adjuvant and acetic acid, and 3 different methods to evaluate the antinociceptive effect on the development of morphine tolerance in mice.

In the formalin-treated animals, the development of tolerance to daily morphine was delayed compared with that in the saline-treated control animals when the antinociceptive effect was measured by the TP method but not the TF method. However, the suppressive effect on the tolerance development was also found even in the TF method when subjects were not confronted with the daily measurement of antinociception. It has been reported that daily repetition of the procedure for assessment modifies the drug effect $(9,10)$, possibly by activation of an intrinsic adaptation mechanism. It is, therefore, plausible that such a mechanism underlies the conflicting results in the TF method. Alternatively, it is well recognized that the neurotransmitters that mediate nociceptive stimuli induced by pressure and heat are substance $P$ and somatostatin, respectively (11); and thereby, the discrepancy in the data obtained by the TP and TF tests may be attributable to the neural system that are involved in the mediation of the stimuli.

The acute inflammatory process consisting of pain sensation following the injection of stimulant progresses towards the recovery stage, as evidenced by the formation of a scar, implying the tendency for a dissipation of pain sensation on the 5 th day. Thus, we have demonstrated that the development of tolerance to morphine is suppressed by the presence of severe pain at the initial stage of inflammation. Evidence supporting this is provided by the fact that when morphine injection was started from 5 days after the formalin injection, tolerance developed in a pattern similar to that in the control animals.

On the contrary, in adjuvant-treated animals, the presence of pain did not affect the development of tolerance in both the TP and TF tests, suggesting the difference in nature between formalin and adjuvant as nociceptive stimulants. Formalin produced a significant swelling of the treated paw lasting for more than 5 days and accompanied with other pathological signs such as redness, removal of hair and finally formation of a scar at the site of injection, while adjuvant produced the same degree of swelling, but this tended to decrease gradually and was not accompanied by any apparent pathological signs (data not shown). Therefore, the severity of the inflammation may also contribute to the production of differences in the results of both stimulants.

Differing from formalin and adjuvant, i.p. injection of acetic acid elicited short lasting pain, manifested as abdominal writhing, by producing acute inflammation in the peritoneal area (12). In this experiment, acetic acid was injected $15 \mathrm{~min}$ before or after morphine administration; i.e., morphine was given in the presence and absence of pain. However, daily morphine resulted in the formation of the same degree of tolerance regardless of time of administration, suggesting that presence of short-lasting and intermittent pain induced by acetic acid did not substantially affect the development of tolerance.

Besides the painful situation induced by chemicals, considerable factors modify the development of tolerance. We have reported that concurrent exposure not only to the electrical foot shock, a physical stress provoking pain, but also to psychological stress prevents the development of antinociceptive tolerance (13). Handling of the animals per se may produce some psychological effect; and experimental pain induced by stimulants, in addition to physical pain, must always be associated with severe psychological stress to the animals. We cannot, at present, provide a reason to explain the discrepancies between the stress- and chemical-induced effects on the development of tolerance to morphine antinociception.

In conclusion, these results suggest that the development of tolerance to narcotics may be modified by various factors, such as the type and intensity of nociception, and also that different results may be produced depending on the test method.

\section{REFERENCES}

1 Colpaert, F.C., Niemegeers, C.G.E. and Janssen, P.A.J.: Nociceptive stimulation prevents development of tolerance to narcotic analgesia. Eur. J. Pharmacol. 49, 335-336 (1978)

2 Colpaert, F.C.: Can chronic pain be suppressed despite purported tolerance to narcotic analgesia? Life Sci. 24, 1201-1210 (1979)

3 Przewlocki, R., Prezewlocka, B., Lason, W., Garson, J., Stala, L. and Herz, A.: Opioid peptides, particularly dynorphin, and chronic pain. In Spinal Opioids and the Relief of Pain, Edited by Besson, J.M. and Lazorthes, Y., Vol. 127, pp. 159-170, Editions Inserm, Paris (1984)

4 Kayser, V. and Guilbaud, G.: Can tolerance to morphine be induced in arthritic rats? Brain Res. 334, 335-338 (1985)

5 Kayser, V., Neil, A. and Guilbaud, G.: Repeated low doses of morphine induce a rapid tolerance in arthritic rats but a potentiation of opiate analgesia in normal animals. Brain Res. 383, $392-396$ (1986) 
6 Portenoy, R.K. and Foley, K.M.: Chronic use of opioid analgesics in non-malignant pain: Report of 38 cases. Pain 25, $171-186$ (1986)

7 Melzack, R.: Human versus pain. The dilemma of morphine. In Advances in Pain Research and Therapy, Edited by Sicuteri, F., Terenius, L., Vecchiet, L., Maggi, C.A., Nicolodi, M. and Alessandri, M., Vol. 20, pp. 149-159, Ravan Press, New York (1992)

8 Costa, M.D.C., Sutter, P.D., Gybels, J. and Hees, J.V.: Adjuvant-induced arthritis in rats: A possible animal model of chronic pain. Pain 10, 173-185 (1981)

9 Kaneto, H., Koida, M. and Tsuchie, F.: Studies on tolerance and physical dependence producing liability of doxepin. Folia Pharmacol. Japon. 68, 704-715 (1972) (Abs. in English)
10 Antelman, S.M., Eichler, A.J., Black, C.A. and Kocan, D.: Interchangeability of stress and amphetamine in sensitization. Science 207, 329-331 (1980)

11 Kuraishi, Y., Hirota, N., Sato, Y., Hino, Y., Satoh, M. and Takagi, H.: Evidence that substance $P$ and somatostatin transmit separate information related to pain in the spinal dorsal horn. Brain Res. 325, 294-298 (1985)

12 Gyires, K. and Knoll, J.: Inflammation and writhing syndrome inducing effect of PGE, PGE and the inhibition of these actions. Pol. J. Pharmacol. Pharm. 27, 257-264 (1975)

13 Takahashi, M., Deguchi, Y. and Kaneto, H.: Blockade of the development of analgesic tolerance to morphine by concurrent treatment with opioid but not non opioid mediated stress in mice. Japan. J. Pharmacol. 46, 1-5 (1988) 